\title{
Global Value Chain Governance and Power Asymmetry between Lead Firms and Suppliers: Case of Apple's Global Value Chain and the State of Its Governance
}

\author{
Shoji Akino ${ }^{1}$, Nobuhiko Yamanaka ${ }^{2}$, Yawen Huang ${ }^{3} \&$ Wataru Kikuchi ${ }^{4}$ \\ ${ }^{1}$ College of Business, Rikkyo University, Tokyo, Japan \\ ${ }^{2}$ Graduate School of Business Administration, Rikkyo University, Tokyo, Japan \\ ${ }^{3}$ School of Economics, Hokusei Gakuen University, Sapporo, Japan \\ ${ }^{4}$ College of Economics, Rikkyo University, Tokyo, Japan \\ Correspondence: Yawen Huang, School of Economics, Hokusei Gakuen University, Sapporo, 2-3-1, \\ Ohyachi-Nishi, Atsubetsu-ku, Sapporo 004-8631, Japan. E-mail: y-huang@hokusei.ac.jp
}

Received: May 12, 2021

doi:10.5539/ijbm.v16n9p58
Accepted: July 20, 2021

Online Published: August 3, 2021

\begin{abstract}
The purpose of this paper is to elucidate modern production systems in which coordination and control among companies have become widespread globally. In particular, the authors aim to test the Global Value Chain (GVC) governance theory empirically with a focus on the state of Apple's GVC governance. More specifically, the authors attempt to determine whether the relationships theoretically explained in Gereffi, Humphrey and Sturgeon (2005) can be observed in Apple's GVC and contribute toward understanding Apple's state of coordination. This study shows the state of coordination in Apple's GVC does not necessarily correspond to the theoretical types. Simply put, the three determinants do not reflect the state of coordination in Apple's GVC. This paper adopts augmenting and complementary explanations from the resource-dependence perspective to elucidate Apple's GVC governance by empirically illustrating how Apple's GVC governance are achieved through the accompanying asymmetric power relationships between the company and its suppliers.
\end{abstract}

Keywords: Apple Inc., explicit coordination, global value chain, governance, power asymmetry, resource dependence

\section{Introduction}

Since the 1990s, the mass production structures of large-scale companies have become increasingly globalized. However, companies are choosing to outsource their manufacturing functions to numerous independent firms on the basis of their location. In addition, production sites that undertake a certain portion of specialized production are being set up across several countries. A substantial number of transactions among these production sites take place via cross-border markets, wherein diverse products are mass-produced under the condition of fluctuating demand. Such production structures are a new feature that have become commonplace, and it can be inferred that exceedingly complicated management has become critical in such mass production structures.

However, research on the globalized mass production at the company level remains insufficient. The formation, realization, and historical positioning of such production and its current state are key topics that warrant deeper analysis. Against the backdrop of these gaps, this study uses a global value chain (GVC) framework critically to evaluate the state of governance in the new production structure that has expanded globally.

GVC research offers concepts that are effective in understanding the various forms of functional integration of internationally dispersed activities. GVC theory includes not only a value analysis of countries or regions and the areas of GVC within which companies act, create value, and obtain value (Dedrick, Kraemer, \& Linden, 2008; Xing \& Detert, 2010; Inomata, 2017), but also a governance analysis that elucidate the control and coordination of entities composing a value chain (Gereffi, Humphrey \& Sturgeon, 2005; Sturgeon, 2008; Ponte \& Sturgeon, 2014; Dallas, Ponte, \& Sturgeon, 2017, 2019). In the latter, the GVC analysis sheds light on both production and the entirety of activities ranging from design to marketing, thus highlighting governance issues concerning the organization and management of these chains of activities. It provides an important perspective that serves as 
reference for the elucidation of this paper's research topic, which seeks to elucidate modern production systems in which coordination and control among and within companies have become widespread.

Based on GVC theory, this study attempts to analyse the modern production systems organized and coordinated as GVC through a case study into Apple's GVC governance. The remainder of this paper is organized as follows. Next section we review the literature that constitutes the origin and evolution of GVC with focus on governance. Third section describes our methodological procedures. Forth section details the state of Apple's GVC: it briefly discusses the formation of the GVC at Apple and then uses interview responses to describe the present state of GVC governance at Apple. Fifth section critically examines GVC governance theory to highlight its existing limitations and presents augmenting and complementary explanations for the state of GVC governance and "power asymmetry" (Gereffi et al., 2005) from a resource-dependent perspective. Final section concludes the paper.

\section{Theoretical Background}

\subsection{The Formation of GVC Governance Theory}

Global value chains are a functional integration of globally dispersed economic activities. However, this functional integration is held within a single organization or takes the form of a network comprising legally independent companies that are not in a direct ownership relationship. Since this functional integration is not spontaneously formed but achieved through the strategies and decision making of specific entities, governance issues regarding its organization and management may arise (Ponte \& Sturgeon, 2014).

In other words, individual companies composing a GVC are economic entities that engage in independent decision making and behaviours, and transactions within such a GVC are considered free contractual actions based on autonomous intent. Assuming each entity acts to further its own gain, functional integration in the GVC will depend on how the potentially conflicting interests of individual companies are coordinated and how the direction to create an end-to-end value chain defined by the companies' actions is formed. The coordination of companies' interests and the setting of direction to ensure functional integration in the GVC is not necessarily based on a democratic consensus or the principles of fairness; rather, it is achieved through inter-firm negotiation and control accompanied by power asymmetry. Governance emerges as a core issue irrespective of whether these objectives are achieved through market pricing mechanisms or hierarchically allocated authority because the functional integration of economic activities depends on interest coordination and direction setting.

In global commodity chains (GCC) research, which is the foundation of the GVC literature, Gereffi (1994) defines governance as the relationship between authority and power that regulates the allocation of financial, physical, and human resources in the chain. Gereffi and Fernandez-Stark (2016) use the concept of GCC to examine production systems that functionally integrate activities such as the development, manufacturing, and distribution of internationally dispersed commodities. They propose two governance structures for GCCs on the basis of companies' intent and actions, which play a crucial role in the organization of GCCs. Gereffi (1994) discusses the producer-driven pattern organized by multinational manufacturing companies, for example, General Motors and IBM, and the buyer-driven pattern demonstrated by major retailers including Sears and Walmart and brand companies such as Nike and Liz Claiborne.

In a special issue on GVC published in the 2001 IDS Bulletin, GVC research is proposed as an integration of analyses on the global economy including GCC and progressed to incorporate studies using networks or the overall chain comprising specialty companies as the unit of analysis from a value chain perspective (Gereffi, Humphrey, Kaplinsky \& Sturgeon, 2001). However, the approach of theorizing governance with focus on the intent and actions of lead firms was carried forward. In the special issue, Gereffi et al. (2001) note that lead firms intervene to coordinate GVCs accounting for two needs. First is the need to determine the specifications of products produced by suppliers and to control the production process. Second is the need to avoid the undertaking of risks associated with suppliers' inability to meet quality standards and deadlines and to exercise their power through decision making and monitoring regarding the control of core resources of their entry into or exit from the chain. Such powerful lead firm do exist through their market power held by lead firms and their favourable positioning the chain.

Further, by exercising such power, lead firms achieve governance from the non-market coordination of economic activities through inter-firm networks, quasi-hierarchical relationships between influential lead firms and companies that are independent yet in subordinate relationships, and vertical integration within companies (Gereffi et al., 2001).

To this effect, Humphrey and Schmitz (2001) propose a GVC governance theory with focus on lead firms' intent 
and actions and define GVC governance as the ability of companies in a chain to set and enforce other companies' operation parameters. In the theory, Gereffi et al.'s (2001) two coordination needs can be considered the setting and the enforcement of product design parameters for supplier products and process parameters for suppliers' manufacturing processes.

Gereffi et al. (2001) and Humphrey and Schmitz's (2001) governance theories focus on the governance behaviour of lead firms and develop their theory on the basis of producer- and buyer-driven governance. With the transformation of inter-firm transactions accompanying ICT advancements since the mid-1990s, numerous forms other than the two types of inter-firm transactions have emerged, creating the need for a theory that can comprehensively explain these phenomena. Accordingly, the focus of governance has shifted from a perspective centred on lead firms in a chain to one reflecting the attributes of inter-firm collaboration (Ponte \& Sturgeon, 2014). Against this backdrop, Gereffi et al. (2005) categorize governance according to the attributes of inter-firm transactions. This framework for governance is frequently cited in the literature and can be considered a standard theory for GVC governance at the company level. The following subsection summarizes the theory.

\subsection{Gereffi et al.'s (2005) Governance Theory}

Gereffi et al. (2005) propose 'a more complete typology of value-chain governance' (p. 83) to construct a framework that overcomes the producer-driven and buyer-driven dichotomy and explains changes in and the development of GVCs. Gereffi et al. (2005) set market transactions and vertically integrated hierarchy as the extremes of explicit coordination and propose three intermediate types of networks between these extremes - modular, relational, and captive - to categorize the five basic forms of GVC governance. They further propose three determinants of GVC governance-the complexity of transactions, degree to which information can be codified, and capabilities of suppliers - to explain the conditions under which the five types of governance are formed. These five types of governance are distinguished by the height of each of the three determinants (Gereffi et al., 2005).

Under the market type, the complexity of exchanged information is low when transactions are easily codified, product specifications are simple, and suppliers have sufficient capabilities. In this case, market governance requires little explicit coordination.

When modularization through codification is possible even for more complex products and when suppliers have the capabilities to supply such modules, there is limited need to directly monitor and control suppliers and complex information can be exchanged with limited explicit coordination. Modular governance is formed under these circumstances.

For relational governance, the exchange of complex information is necessary and product information cannot be easily codified, although suppliers are equipped with high capabilities. Here, tacit knowledge is exchanged between sellers and buyers and inter-dependent relationships are regulated through reputation and social ties. Such complex and tacit information or knowledge is exchanged through frequent direct interactions in relationships controlled through a high degree of explicit coordination.

Governance takes a captive form when an information exchange in the form of detailed instructions and procedural documents is highly codified and if product specifications are increasingly complex, while supplier capabilities are low. High product complexity and low supplier capabilities warrant considerable intervention and control by lead firms, although this increases suppliers' transactional dependence on the lead firms to secure the gains of their coordination efforts. Suppliers under captive governance are often restricted to activities in limited domains and depend on lead firms for complementary activities such as design, logistics, component procurement, and production technology innovation. While suppliers under captive governance are controlled by lead firms, dissolving such relationships it not viable because the lead firms offer resources and market opportunities.

Finally, when the codification of product specifications is difficult, products are complex, and there are no capable suppliers, lead firms are forced to internalize production, resulting in the formation of hierarchy-based governance. Hierarchy governance requires the exchange of tacit knowledge through the value chain and is formed when it is necessary to control intellectual property and effectively manage the complex networks of inputs and outputs.

Gereffi et al. (2005) use the five governance types to explain the degree of explicit coordination and power asymmetries between lead firms and suppliers. They describe the degrees of power asymmetry and explicit coordination as a continuum from the highest degrees in a hierarchy to the lowest ones in market governance. In captive governance, the power of a lead firm is directly exercised in a hierarchical manner, implying a high 
degree of explicit coordination and significant power asymmetry. By contrast, in relational governance, the power relationship is more symmetric and explicit coordination occurs through frequent dialogue. In modular and market governance, switching costs are low for lead firms and suppliers and the power asymmetry is lower (Gereffi et al., 2005).

In Gereffi et al.'s (2005) governance theory, the exercising of power and explicit coordination by lead firms, which had been at the core of theory, are considered attributes of each governance type and theorized as explainable by the three determinants. In Gereffi et al.'s (2005) theory of GVC governance and its subsequent development, governance type based on inter-firm relationships composed of lead firms and suppliers is regarded as governance theory at the micro level and the scope of explanation is further extended to the meso level and the macro level. The meso-level theory explains the propagation of inter-firm governance relationships within the value chain. The macro-level theory, on the other hand, discusses socioeconomic and environmental changes resulting from the state of GVC governance. Thus, attempts have been made to construct a more comprehensive GVC governance theory at the micro, meso, and macro levels (Sturgeon, 2008; Ponte \& Sturgeon, 2014). (Note 1)

While the GVC governance theory goes ahead with the abovementioned theoretical extension, it still maintains Gereffi et al. (2005) as a reference for GVC governance at the company level. Following Gereffi et al. (2005), Sturgeon (2008) and Ponte and Sturgeon's (2014) extend GVC governance theory to seek a more comprehensive explanation. Further, to address the gap in GVC governance research on the issues of power, Dallas et al. (2017, 2019) develops a power typology that functions in GVC governance. However, here as well, power relationships between lead firms and suppliers are explained as per Gereffi et al. (2005).

Thus, while it carries forward the framework for GVC governance at the company level, Gereffi et al. (2005) remains the basis for GVC governance between lead firms and suppliers. Simply put, Gereffi et al.'s (2005) theory can be viewed as a standard theory of corporate-level GVC governance. (Note 2) As mentioned before, this paper uses the GVC theory critically to analyse the state of GVC governance at the corporate level. This means that the present study can be viewed as an empirical test of the GVC governance theory with focus on the state of Apple's GVC governance.

\subsection{Analytical Framework for GVC Governance}

Prior to conducting the analysis, we discuss the types of events and relationships adopted as this study's subjects on the basis of Gereffi et al.'s theory (2005).

As previously mentioned, Gereffi et al. (2005) state that each governance type is formed through three determinants. These determinants can be considered independent variables, while the governance types are dependent variables. We first examine the domains these determinants represent in the state of Apple's GVC governance. Second, we clarify the type of governance corresponding to the state of Apple's GVC governance. Gereffi et al. (2005) define the differences among governance types as variations in the relationship between lead firms and its supplier and those in the approach to explicit coordination. Accordingly, this research describes the relationships between Apple and its suppliers; explicit coordination by Apple; and the methods, targets, and characteristics of coordination. Finally, we verify the relationship between the determinants and governance types using Apple's GVC as a case study. More specifically, we attempt to test whether the relationships theoretically explained in Gereffi et al. (2005) can be observed in Apple's GVC and contribute toward understanding Apple's state of coordination.

The following section clarifies the state of Apple's GVC, which will help understand the topics discussed in Fourth section.

\section{Methodology}

\subsection{Research Design}

The governance analysis in this study focuses on Apple and its GVC. The choice of Apple and its GVC as an object of this case study was motivated by several reasons. First, this choice was motivated by the fact that Apple outsources a majority of its manufacturing functions to external companies with no direct ownership relationship, thus engaging in mass production through a supply structure comprising numerous manufacturing companies located across the world. In FY 2018, for example, Apple sold more than 200 million units of its core product, iPhone. Second, Apple's production structure and its role in growth achievement make Apple a unique case study. Apple's mass production structure consists of new features that significantly differ from traditional ones, which lets us view the company as a revelatory case. Third, integrating these new features in production structure and GVC governance theories renders Apple a critical case in demonstrating the validity of GVC theory and in 
extending or modifying alternative explanations and theories. Finally, Apple also fulfils the condition prescribed by Yin (2003), that is, a single case study is an appropriate approach to testing a theory. (Note 3)

Since the aim of this study was to clarify the state of Apple's GVC, we have decided that a qualitative study would be the appropriate methodological approach. The main technique used in the gathering of data was the interviews conducted with Apple and other suppliers in the IT industry, although, this as complemented by the written responses to questionnaire conducted with other suppliers and numerous academic sources.

\subsection{Data Collection}

Data for the present case study were primarily collected through interview surveys administered to a Taiwanese supplier that has been transacting with Apple for several years, Company A. We also referenced the extant literature and other sources. (Note 4)

Company A supplies electronic components used in smartphones, tablets, and other devices and significantly depends on Apple for its sales. According to the categories of company scale prescribed in Taiwan, Company A is a large-scale company in terms of capitalization and number of employees. Its components are delivered to module suppliers that embed them in module components sent to Electronics Manufacturing Service (EMS), which builds module components for Apple products. This study also uses data from interviews conducted in a Taiwanese procurement subsidiary of a Japanese electric machinery manufacturer, Company B, and EMS, Company C. Surveys were conducted between March and August 2019 for companies A and C and in March 2019 for Company B. The duration of each interview was roughly two hours. To protect the suppliers' identity, all related information including company name and product is kept confidential. See Table 1 for a detailed case data.

Table 1. Description of case data

\begin{tabular}{llll}
\hline \multicolumn{2}{l}{ Description of Case Data } & & \\
\hline Company & Category & Time & Interviewees \\
A & Supplier & March, 2019 & Two interviewees: \\
& & Interviewee 1: Responsible for R\&D \\
& & Interviewee 2: Responsible for Quality Control \\
& August, 2019 & Three interviewees: \\
& & Interviewee 1: Responsible for R\&D \\
& & Interviewee 2: Engineer \\
& & & Interviewee 3: Engineer \\
B & Electric machinery manufacturer & March, 2019 & One interviewee: Project Manager \\
& EMS & March / August, 2019 & One interviewee: Responsible for sourcing and purchasing \\
\hline
\end{tabular}

\section{State of Governance in Apple's GVC}

\subsection{GVC Formation and Development}

This subsection first presents the formation and the current state of the GVC at Apple. Following its inception in 1976, Apple achieved significant growth throughout the 1980s, and by the first half of the 1990s, it established a production system comprising four production sites organized by region: the Sacramento and Fountain plants in the United States serve North and South America; the Singapore plant caters to Australia, Japan, and the rest of Asia; and the Ireland plant supplies to Europe. However, the company suffered a significant sales decline and loss in 1996 and thereafter, business remained stagnant until the first half of the 2000s. Apple's performance gradually recovered and since the latter half of the $2000 \mathrm{~s}$, it has reported exponential growth into a giant corporation. During its progress from stagnation to rapid growth, Apple advanced its outsourcing and globalization to develop its present-day GVC.

Akino (2016) surveys changes in Apple's production structure during the stagnation period and shows that as part of its restructuring, the company cut off its in-house production functions and outsourced nearly all of its products. In 1996, U.S.-based SCI Systems purchased Apple's Fountain plant and was outsourced production. Apple also outsourced circuit board assembly and numerous products to manufacturers in Singapore and South Korea, gradually reducing production at its three plants. The production of remaining models was incrementally outsourced, and by 2004, manufacturing was discontinued at the Singapore and Sacramento plants. The Ireland plant, which produces Mac computers, is the only Apple plant that retains its manufacturing functions. During 
this period, Apple outsourced its manufacturing particularly to Electronics Manufacturing Service (EMS) in Taiwan. Until 2002, Hon Hai Precision Industry handled the production of all units for iMac models. In 1995, Apple concluded an original design manufacturer (ODM) agreement with Taiwan's Quanta Computer for a series of PowerBook models. The agreement was extended into the 2000s and expanded to the production of the new model of iBooks. The iPod series, which supported Apple's rapid growth from the latter half of the 2000s, was outsourced in entirety to Inventec Appliance Corporation since the product's launch in 2001. The rapid increase in iPod sales by 2004 prompted Apple to expand its procurement sources to AsusTek Computer and Hon Hai Precision.

Thus, Apple's production structure, which was an outcome of restructuring in the latter half of the 1990s, shifted from in-house production to outsourcing production functions to external firms, achieving mass production. In response to the shift in product strategy, company diversified its business fields into non-PC products such as the iPod, iPhone, and iPad, which has contributed to Apple's rapid growth since the 2000s. Further, Apple concluded agreements with the then-growing EMS companies and entered into agreements with numerous independent manufacturers for material, parts, and components. Apple's newly established production structure and GVC resulted in the manufacturing companies setting up and expanding production sites primarily in China, which has led to the present-day situation of the multinational technology company.

An Apple supplier list published in early 2019 lists 808 worksites under 200 companies, which accounts for $98 \%$ of Apple's procurement costs. These companies include contract manufacturers that primarily engage in assembly and those manufacturing numerous materials, parts, and components. Apple's suppliers are based in 13 countries, with production sites and other business locations spread across 28 countries. Of the 200 suppliers, 42 are based in the United States, 45 in Taiwan, 44 in China, and 38 in Japan. Overwhelming 380 worksites are located in China and 128 work sites are based in Japan. Evidently, Apple has been building a global production structure comprising multiple independent suppliers (Akino, Yamanaka, Kikuchi, \& Huang, 2020).

In addition to Apple's dependency on the manufacturing functions of external companies, which can be seen as the company's pursuit of outsourcing, there is an apparent trend toward the strengthening and internalizing of manufacturing related functions. Apple manufactures a certain portion of Mac computers at its Ireland plant, although these manufacturing functions account for a small portion of the whole. Apple not only designs its products' external and internal components, but also is deeply involved in the invention and design of technologies for specialized manufacturing processes. The company also designs the core IC components of the iPhone and iPad. Thus, Apple has positioned itself in the upstream areas of the development and design for manufacturing methods and equipment through mergers and acquisitions and active internalization. This can be viewed as Apple distancing itself from the manufacturing functions at the middle of the value chain. (Note 5)

The following subsection discusses how Apple, in its current position in the value chain, coordinates and integrates a GVC comprising independent external companies with manufacturing functions and how it has succeeded in mass-producing diverse product groups.

\subsection{State of Governance}

The typical forms of transactions between EMS companies and the brand manufacturers in the supply chain are turnkey and assign. In the turnkey form of transaction, EMS companies select and manage suppliers for parts procurement, and this reduces brand manufacturers' cost of searching for suppliers. Under assign, the brand manufacturer selects, approves blueprints, and negotiates price with suppliers to procure parts. Company B reports that assign and turnkey account for $80 \%$ and $20 \%$ transactions for general PCs and $90 \%$ and $10 \%$ for high-spec PCs. Brand manufacturers prefer assign transactions for high-cost parts that are closely related with product quality and shared among multiple products. Bulk purchases of parts that must be shared increase brand manufacturers' bargaining power with the suppliers and reduce unit price.

For assign transactions, Apple requires its suppliers to provide detailed information about materials and parts costs, labour costs, and profits. For example, when a specific part is produced through multiple processes, Apple may request estimates for each process. Company A states that customers other than Apple determine prices of parts as per the market price. Apple, however, requests for information that is exceptional in amount and scope and uses such detailed information to select suppliers and determine baseline prices. Prices negotiated between Apple and Company A are then communicated to EMS companies and module suppliers.

Between Apple and Company A, Apple primarily designs parts, although Company A's development department may also engage in some design activities. Company A's development department coordinates with its manufacturing department while engaging in continuous negotiations with Apple. For final determined parts, decisions are made concerning the extent of internal manufacturing by Company A and the extent of external 
procurement. When Company A externally procures parts, Apple mandates the confidentiality of the final product. In certain cases, Apple may supply parts to Company A; for example, all electronic parts are supplied to Company A by Apple. Apple estimates the procurement amount when finalizing parts specifications. However, the estimated procurement volume is only a planned amount, and does not carry binding force.

Apple imposes significantly higher standards for manufacturing precision and quality control than those defined by other brand manufacturers, and always requires that problem resolution be based on verification through experimentation. Occasionally, suppliers are unable to meet Apple's standards, in which case, it offers ideas while urging all suppliers to achieve the desired results. Company B states that Apple has very powerful capabilities for assessing suppliers' initiatives.

When a supplier commences production, Apple representatives may offer support for two or three months. This kind of support is not unique to Apple; For example, Company B, too, may inspect the production lines of its partner EMS companies and provide suggestions to improve production methods. Following the successful launch of the production, Apple requests that the supplier store several weeks' worth of inventory close to EMS companies' production sites, the destination of the supplier.

At several points in time, the supplier receives notification of planned purchase quantity, known as a forecast. Every month, Apple notifies the supplier of planned purchase quantities for a six-month period as a long-term outlook. However, this forecast provided by Apple does not guarantee its purchase quantity of the parts. Company A uses such forecasts when considering the required materials and parts volumes. All notifications regarding official prices, quantities, and delivery dates are provided by EMS companies or module suppliers about a month prior to commencing production.

Looking at the handling of fluctuations in demand, Apple forecasts its unit sales for products and presents forecasts to Company A. However, there is a wide gap between Apple's forecast and actual volume ordered. According to Company A, actual unit sales often differ by as much as $50 \%$. Company A is required to immediately deliver parts when unit sales exceed Apple's forecasts but must shoulder the impact when unit sales fall short of forecasts. Sometimes suppliers are required to set up plants dedicated to Apple. However, suppliers face the risk of declining sales for Apple products and must increase orders from other customers to maintain the plants' utilization rates. Apple offers no compensation for parts procured by Company A even if sales performance falls short of the forecasts and there is a decline in actual orders.

Looking at the method by which unit prices are determined, baseline unit prices are determined by Apple and Company A as described above. Apple promotes competition by presenting estimates to multiple suppliers. Actual delivery price is determined between EMS companies or the module suppliers and Company A. Once the price is fixed, EMS companies or the module suppliers place individual orders with Company A. Company A must deliver the orders by the predetermined delivery date and to the production site specified by EMS companies or the module suppliers. Upon commencing mass production, Company A must engage in quarterly unit price revisions with Apple. A similar price revision approach is also taken for Company B and its suppliers. Apple presents Company A with a target cost, following which the unit price is revised through negotiations. Apple, however, demands severe cost reductions from Company A and the cost reduction rate is high compared with those quoted by other brand manufacturers. While Company A states that it often resists Apple's demands, it is generally forced to comply.

Looking at oversight of Company A by Apple, Apple's buyers make observation visits once a month before Company A begins mass production. Once Company A has initiated the process, Apple pays a visit when production is at its peak to confirm if the demanded volume will be delivered. Company A states that Apple makes the most frequent visits among all its customers. Apple's supplier audits include both regular and unannounced audits. Apple also requires suppliers to adopt an inventory management system where they can share real-time information on production processes, shipment timings, and the arrival of materials. According to Company A, such a requirement is proposed by most major customers, not only Apple. Company $\mathrm{C}$ is also subjected to observation visits by Apple and believes the standards imposed by Apple are notably higher that those by other customers. It also states that higher quality demands are correlated with a greater number of observations.

Apple's governance toward Company A is closer than that of Company B toward its partner EMS. Company B does not request its partner EMS to invest in the production of specific products. Company B considers its partner EMS can achieve the required quality standard at the determined unit price. Notably, it has no objection to using parts produced for other companies' products; rather, it positively evaluates such parts since they do not require testing and verification as in the case of new parts. However, Apple may mandate that certain production 
equipment be used exclusively for the production of its products. While Apple itself may invest in such equipment, business relations with the company often require transaction specific investments. The strictness of the standards that Apple demands of suppliers can be glimpsed from these facts.

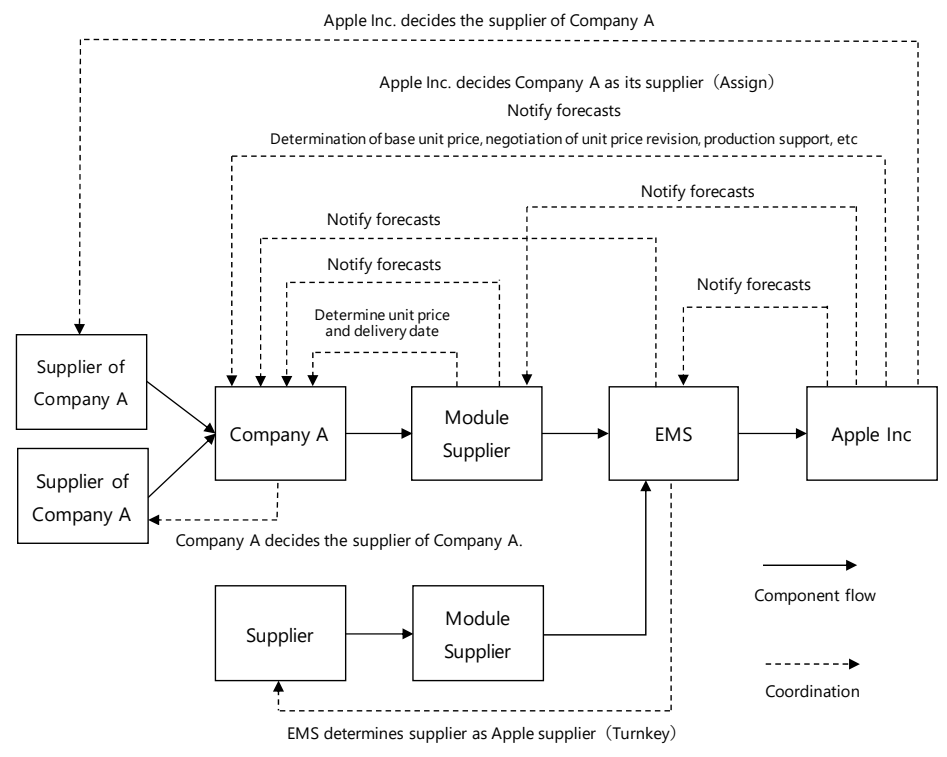

Figure 1. State of Apple's governance toward company A

Source: Prepared by authors using interview data.

Figure 1 summarizes the state of Apple's governance, whose key features are the scope and strictness of control. Apple's governance is not limited to EMS companies or the module suppliers but extends to Company A, which supplies parts to EMS companies and the module suppliers. Company A also highlights that the scope of control by other brand manufacturers is limited to EMS companies and the module suppliers and does not extend to Company A.

\section{Discussion}

\subsection{Discussion Based on GVC Theory and Related Concepts}

We consider the state of Apple's governance from the perspective of governance types defined in Gereffi et al. (2005). The first independent variable used to determine governance type is the complexity of transactions. To achieve product differentiation, Apple makes numerous demands toward suppliers, and these include parts specifications, price, quality, and delivery time. Thus, the complexity of information can be deemed as high. The second independent variable is the possibility of codification. Transactions for modularized products such as the iPhone and iPad have well-defined product specifications and quality, and thus, superior ability is needed to codify information. The third independent variable is the capabilities of suppliers. Company A's production process requires considerable time and high technological capabilities. Given that Company A has been successfully supplying to Apple for several year, it is reasonable to assume that its production and management capabilities are not low. The high complexity of transactions, superior ability to codify information, and high supplier capabilities are characteristic of modular governance. This is in line with Gereffi et al. (2005), who state that in modular governance, while the complexity of transactions is high, there is superior ability to codify information and thus, complex information is exchanged without explicit coordination. Modular governance limits the power asymmetry between lead firms and suppliers.

However, the interview responses indicate that Apple's governance is characterized by unilateral coordination. Apple leads product design and cost determination and imposes close control and strict authority over the manufacturing processes. Company A recognizes that they can't resist such powerful control by Apple. Against the backdrop of governance types, the state of Apple's coordination presents captive mode of governance. As per modular governance, Apple's intervention in the operations of EMS companies and module manufacturers should be limited. However, Apple exercises considerable involvement that extends to Company A, which supplies to EMS companies and module manufacturers. The state of Apple's GVC governance cannot be sufficiently explained using Gereffi et al.'s (2005) framework. 
The state of coordination in Apple's GVC does not necessarily correspond to the five governance types. This is possibly because the three determinants are not suitable as independent variables for governance types. In other words, the captive condition, observed as a state of explicit coordination in Apple's GVC, does not match the governance type derived from the height of the three determinants indicated by the state, that is modular type. Simply put, the three factors do not reflect the state of coordination in GVC.

Let us return to the state of Apple's coordination, and the fact that, in comparison with other brand manufacturers, Apple exerts strict coordination functions on its suppliers in the GVC. The occurrence of such a coordination state can be attributed to the asymmetric inter-firm relationships between Apple and its suppliers and the power asymmetries described in Gereffi et al. (2005). Accordingly, GVC governance can be elucidated not by a coordination state fitted to the height of the three determinants, but by the types of inter-firm asymmetric relationships among the transacting parties and the forms of coordination therein. It can be considered that Gereffi et al.'s (2005) three determinants are derived from the relationships among the transacting parties and the forces relative to the industry as a whole. Thus, it is imperative to first continue an analysis of the coordination state in GVC and clarify its relationship with inter-firm power and power asymmetry and then critically examine the existing concepts. These efforts will help reconstruct an appropriate concept that elucidates the state of coordination. While this study is unable to resolve the issues in entirety, it sheds light on the relationships with companies that compose the GVC using Apple's GVC governance as a case study.

\subsection{Resource-Dependent Relationships and Power Asymmetries in GVC}

The functional integration of economic activities in a GVC is achieved through transactions among individual firms that engage in economic activities. These transactional relationships, in turn, form networks of inter-dependent relationships. In Apple's state of coordination, inter-dependent relationships in the GVC imply explicit and strict coordination. This form of coordination can be attributed to the asymmetric relationships of power between the lead company, which organizes and leads the inter-dependent relationships, and other companies and not to reciprocal and equal market transactions or exchange relationships.

Pfeffer and Salancik (1978/2003) offer a helpful explanation for inter-firm inter-dependent relationships and power relationships. (Note 6) Drawing on the existing issues of GVC governance theory, this study adopts augmenting and complementary explanations from a resource-dependence perspective to elucidate Apple's GVC governance.

Resource-dependent relationships among companies and other economic entities are defined as a chain of transactions in which resources that become inputs are procured from the market and output is supplied through production activities, thus generating profits. Since companies are not entirely self-fulfilling or self-sufficient in executing their activities, they rely on other companies, organizations, and individuals to obtain the necessary resources or secure revenue needed to survive. (Note 7) However, companies are essentially economic entities that pursue their self-interest and seek to maximize their own profits while engaging in inter-dependency through resource exchanges. Accordingly, a resource-dependent relationship involves the negotiation of interests accompanied by potential conflicts, and whether such a negotiation is resolved in a manner advantageous to a company is determined by the type of resource-dependent relationship formed.

Resource-dependent relationships are not necessarily limited to symmetric inter-dependency relationships. The resource-dependence perspective assumes that inter-firm, resource-dependent relationships result in asymmetric power relationships. To elaborate, companies with an advantage over other firms may exercise power to constrain the decision-making process and to control the actions of more dependent companies in order to advance negotiations in their favour. On the other hand, companies that are solely dependent must take a subordinate position in decision-making processes, actions, and the securing of interests. Thus, identifying factors influencing such inter-dependency is of strategic importance.

Pfeffer and Salancik (1978/2003) list three determining factors in a resource-dependent relationship. First is the importance of resources that emphasizes the degree of significance assigned to resources in the continuity and survival of a company's business activities. The importance of resources is further divided into two dimensions: the relative magnitude of resource exchanges and the criticality of resources. The relative magnitude of a resource is defined as the percentage of an organization's total input or output in a resource exchange. Companies that source a majority of their raw materials from a single entity are more dependent on their suppliers than those with multiple procurement sources. In addition, single-product companies are more dependent on their customers than are diversified companies. The criticality of a resource is an important concept in that a shortage of a resource exerts a direct and critical impact on the company's survival. The greater the number of resources for which a company depends on another company, the higher the criticality of those 
resources and the more the constraints and controls imposed on the organization by such company (Pfeffer \& Salancik, 1978/2003).

Second, dependence relationships are defined by the extent of discretion other organizations exercise in allocating and using resources. Companies generally have to depend on an organization if it controls resource allocation and use. Simply put, control over the allocation and use of resources is a source of power over other organizations, and it becomes a more pronounced source of power when resources are scarce. This control over the allocation and use of resources is first enabled by the ownership of resources, which enables control over the use and disposal of the resources. Conversely, even if the resources are not owned, restricting access to information or managing access to resources through a membership enables control over resource allocation. The actual use of a resource determines user discretion. Finally, establishing and enforcing rules or regulations for resource ownership, allocation, and use enables control over resource allocation and use (Pfeffer \& Salancik, 1978/2003).

Third, dependence is defined by the ability to use substitute resources and by the extent to which these substitute resources are controlled by other organizations. Dependence increases when there are challenges involved in using substitute resources. The concentration of resource control among a small number of organizations and the monopolizing of transactions by these organizations constrain the search for and use of substitute resources, thus increasing dependence (Pfeffer \& Salancik, 1978/2003).

From this resource-dependence perspective, the state and coordination of Apple's GVC governance are achieved through resource-dependent relationships between the company and its suppliers and through the accompanying asymmetric power relationships. Thus, this study examines the resource-dependent relationships formed between Apple and its suppliers and how this has resulted in power asymmetry.

The analysis first focuses on resource-dependent relationships surrounding critical resources. Company A is dependent on Apple for a significant portion of its revenue. While Apple may view this relationship as transactional, these transactions are a major source of revenue for Company A and the loss of such transaction opportunities could jeopardize the company's survival. In other words, Company A views transaction opportunities with Apple as an extremely critical resource, thus forcing a highly dependent relationship.

As previously mentioned, Apple has outsourced a bulk of its manufacturing functions while aggressively internalizing development and design functions related to products and manufacturing processes. Consequently, Apple not only organizes the GVC but also internally secures the most critical functions in the GVC, thus increasing the dependence of suppliers such as Company A. In other words, resources and functions that are the most critical to value creation in Apple's GVC are owned and executed by Apple.

Second, this study examines discretion exercised in resource allocation and use. Apple freely exercises discretion in allocating and using diverse resources in the GVC. Further, it possesses the technical know-how and knowledge to internalize product development and design functions and controls them through confidentiality clauses. This further reinforces the criticality of Apple's functions and technical knowledge in the GVC, heightening supplier dependence.

Company A is required to not only provide detailed information on production, costs, profits, and processes, but also comply with Apple's strict confidentiality standards. Thus, information about Company A's business activities and capabilities is unilaterally absorbed and accumulated within Apple, forming a clear information asymmetry between Apple and Company A. Apple can also strategically use this information asymmetry in negotiations with Company A. Further, Company A must be added to Apple's supplier list to gain critical transaction opportunities. However, Apple has the sole power to make this decision and thus, controls access to transaction opportunities through GVC memberships. These circumstances further increase the company's dependence on Apple. Apple also strictly controls and monitors Company A, particularly its inventory and related responsibilities: Apple requests for exclusive use of factories, considerable cost reductions, and conducts frequent audits (including unannounced audits). Apple's control over Company A's resource use constrains the extent to which Company A can exercise discretion in resource usage.

Finally, this research considers the substitutability of resources. Transaction opportunities with Apple account for a significant portion of Company A's revenue and cannot be substituted with those offered by other customers, which strengthens the criticality of transaction opportunities with Apple and increases reliance on Apple. Apple's exclusive use of Company A's production equipment limits alternative revenue opportunities, which further strengthens Company A's degree of dependence on transactions with Apple. Moreover, Apple's functions in the GVC are essential in the supply of highly differentiated and high-quality products and its know-how is a non-substitutable resource for Company A and other suppliers in the GVC. These factors enhance the criticality 
of Apple's resources and transaction opportunities and strengthen the dependence on and the power held by Apple in the GVC.

In sum, Company A is highly dependent on Apple for all the determinants of a resource-dependent relationship. The individual factors contributing to this dependence exert a combined interrelating effect, which heightens Company A's overall dependence on Apple. Apple's coordination functions in the GVC are multifaceted and extensive, (Note 8) and Company A's strong dependence on Apple results in a significant power asymmetry, through which Apple can realize its strict control and coordination. This study references Gereffi et al. (2005) and their theorization of three determinants of governance: complexity of transactions, ability to codify information, and capabilities of suppliers. However, the state of Apple's coordination reveals that, independent of these, GVC coordination is achieved through asymmetric resource-dependent relationships between the lead firm and suppliers and the resultant power asymmetry. It is, therefore, necessary to explain why GVC coordination by the lead firm, independent of the determinants of governance types, is strategically based on asymmetric power relationships and to examine the conditions and factors contributing to such governance behaviour.

\section{Conclusions}

This study attempts to elucidate present-day mass production systems in which coordination and control are widespread between and within companies by critically reviewing GVC research and using Apple as a case study. According to the extant GVC literature, the manner in which the internationally dispersed chain of activities by numerous independent companies is functionally integrated raises a governance issue, it offers an effective perspective on the control and coordination of entities composing the value chain. Thus, we believe that GVC research, including Gereffi et al. (2005), provides a useful and critical viewpoint necessary to elucidate the topics addressed in this study. Such a perspective can clarify modern production systems in which governance within companies and inter-firm relationships has gained much significance.

By reviewing critically existing theory on GVC governance, this study has, to a certain extent, clarified the state of Apple's GVC governance and its rigorous coordination. Importantly, the findings reveal that this state of governance does not necessarily correspond to those determinants described in Gereffi et al.'s (2005) framework. Therefore, considering the need to explain the state of coordination in terms of power relationships among transacting parties in a GVC, this study explains the state of coordination from the resource-dependence perspective. The research concludes that, independent of the three factors of Gereffi et al. (2005), it is possible to interpret that Apple achieves its close coordination and strict control through asymmetrical power relations brought about by asymmetrical resource dependencies with supplier firms. In this respect, the analysis of GVC governance by the resource dependence perspective can be considered to relativize the typology based on determinants in Gereffi et al. (2005) and to complement their GVC theory.

Despite the contributions of this study, its conclusions are subject to several limitations. First, the analysis is limited to a part of Apple's GVC and does not describe the whole. Future research should consider increasing the number of cases and accounting for a more extensive range of conditions through the use of questionnaires. Second, this study focused on suppliers' site in GVC. We have also compared Apple's governance with Company B toward its partner EMS. In spite of this, there is a lack of data collection on Apple site. Thus, we need further research on Apple's site to describe the state of governance in GVC. From a theoretical viewpoint, more thorough research on GVC governance is needed. Scholars should conduct a more detailed examination of the three determining factors and five governance types listed in Gereffi et al. (2005) and extend the concept of coordination to broader research. Moreover, it is necessary to deepen discussions on GVC governance considering the recent trends in governance research such as Ponte and Sturgeon (2014). Finally, while this study empirically relies on the resource-dependence perspective to examine power asymmetries, this approach is problematic. Further research is needed to explore broader frameworks that can shed light on the factors determining GVC governance.

Nevertheless, we believe that the findings of this study highlight certain gaps in GVC governance research and can serve as a basis to further examine the state of coordination from the perspective of power relationships and to design effective approaches to address the issues identified in this study. 


\section{References}

Akino, S. (2015). Apple sha no seicho katei to seisan taisei no genjo ni kansuru kenkyu [A Study on the Growth Process and the Present Situation of the Production System in Apple Inc]. Rikkyo Business Review, 8, 41-60. https://doi.org/10.14992/00012367

Akino, S. (2016). Apple Computer sha ni okeru seicho katei to jigyo kozo no tankan [Analysis on the Growth Process and the Transformation of the Business Structure: The Case of Apple Computer Inc]. Journal of Industrial Management Research, 30(1), 73-84.

Akino, S., Yamanaka, N., Kikuchi, W., \& Huang, Y. (2020). Apple sha ni okeru Global Value Chain no jittai ni kansuru kenkyu: kachi bunseki wo chushin ni [A Study on Global Value Chain of Apple Inc.: Focus on Value Analysis]. Journal of Industrial Management Research, 34(1), 30-45.

Dallas, M. P., Ponte, S., \& Sturgeon, T. J. (2017). A Typology of Power in Global Value Chains. Working Paper in Business and Politics, 92, 1-35. https://doi.org/10.1080/09692290.2019.1608284

Dallas, M. P., Ponte, S., \& Sturgeon, T. J. (2019). Power in Global Value Chains. Review of International Political Economy, 26(4), 666-694. https://doi.org/10.1080/09692290.2019.1608284

Dedrick, J., K. Kraemer, \& G. Linden. (2008). Who Profits from Innovation in Global Value Chains? A Study of the iPod and Notebook PCs. Paper presented at the Sloan Industry Studies Annual Conference, Boston. http://dx.doi.org/10.2139/ssrn.1125024

EMJ Incorporated. (2016). Smartphone no sekai shijo to Supply Chain: Chosa hokokusho [Global Smartphone Market and Supply Chain: Research Report]. EMJ Incorporated.

Gereffi, G. (1994). The organization of buyer-driven global commodity chains: How U.S. retailers shape overseas production networks. In Gereffi G. \& Korzeniewicz M. (Eds.), Commodity Chains and Global Capitalism (pp. 95-122). Praeger.

Gereffi, G. (2001). Beyond the Producer-driven/Buyer-driven Dichotomy: The Evolution of Global Value Chains in the Internet Era. IDS Bulletin, 32(3), 30-40. https://doi.org/10.1111/j.1759-5436.2001.mp32003004.x

Gereffi, G., \& Fernandez-Stark, K. (2016). Global Value Chain Analysis: A Primer. (2nd ed.). Duke University Center on Globalization, Governance \& Competitiveness.

Gereffi, G., Humphrey, J., Kaplinsky, R., \& Sturgeon, T. (2001). Introduction: Globalization, Value Chains and Development. IDS Bulletin, 32(3), 1-8. https://doi.org/10.1111/j.1759-5436.2001.mp32003001.x

Gereffi, G., Humphrey, J., \& Sturgeon, T. (2005). The Governance of Global Value Chains. Review of International Political Economy, 12(1), 78-104. https://doi.org/10.1080/09692290500049805

Hatch, M. J. (1997). Organization Theory: Modern Symbolic and Postmodern Perspectives. Oxford University Press.

Humphrey, J., \& Schmitz H. (2001). Governance in Global Value Chains. IDS Bulletin, 32(3), 19-29. https://doi.org/10.1111/j.1759-5436.2001.mp32003003.x

Inomata S, (2017). Analytical Frameworks for Global Value Chains: An Overview. In Dollar, D., Guilherme, J. R. and Wang, A. (Eds.), Global Value Chain Development Report 2017: Measuring and Analyzing the Impact of GVCs on Economic Development (pp. 15-35). Word Bank Group.

Pac Rim Research. (2012). Apple- Foxconn buhin chotatsu senryaku zenchosa: iPhone iPad buhin Supply Chain no zenyo [Apple-Foxconn Parts Procurement Strategy: Overview of iPhone and iPad Parts Supply Chain]. Pac Rim Research.

Pfeffer, J., \& Salancik, G. R. (1978/2003). The External Control of Organizations: A Resource Dependence Perspective. Stanford University Press.

Ponte, S., \& Sturgeon, T. (2014). Explaining Governance in Global Value Chains: A Modular Theory-Building Effort. Review of International Political Economy, 21(1), 195-223. https://doi.org/10.1080/09692290.2013.809596

Sturgeon, T. (2008). From Commodity Chains to Value Chains: Interdisciplinary Theory Building in an Age of Globalization. Industry Studies Association Working Paper Series, WP-2008-02, 1-35.

Xing, Y., \& Detert, N. (2010). How the iPhone Widens the United States Trade Deficit with the People's Republic of China. ADBI Working Paper, 257. Tokyo: Asian Development Bank Institute. 
Yin, R. K. (2003). Case Study Research: Design and Methods (3rd ed.). Sage Publications.

\section{Notes}

Note 1. More accurately, studies have presented new theoretical viewpoints on GVC governance that are not limited to the scope of phenomena subject to theorization using diverse theoretical knowledge. Ponte and Sturgeon (2014), for example, incorporate governance as a normalizing factor while drawing on conventional theory and position it as a module that offers a more comprehensive explanation of GVC governance theory.

Note 2. Sturgeon (2008) highlights that the initial theorization of GVC governance culminated in Gereffi et al. (2005). This viewpoint supports this study's recognition that GVC governance theory at the company level was somewhat complete in Gereffi et al.'s work.

Note 3. Yin (2003) highlights three cases in which an appropriate theory testing method can be determined: critical, extreme, and unique. The author further discusses the significance of a revelatory case.

Note 4. The primary data sources include EMJ Inc. (2016) and Pac Rim Research (2012).

Note 5. Some examples of in-house manufacturing include equipment for color plastic used in the iPhone 5C, laser processing equipment and milling machines for MacBook aluminium bodies, and gear inspection equipment for iPhone and iPad camera lenses. As for product development, Apple acquired U.S.-based semiconductor design companies PA Semi and Intrinsity and thus, internally designs application processors that have been at the core of the iPhone and iPad since the iPhone 4. In addition, the virtual AI assistant Siri, which debuted with the iPhone 4S, was created by the acquired U.S.-based company Siri (Akino, 2015).

Note 6. The resource-dependent perspective is positioned as one of the most influential theories related to the relationship between an organization and its environment (Hatch, 1997).

Note 7. In the resource-dependent perspective, the term 'resources' is given various meanings. Broadly, resources can be defined as physical or monetary resources including raw materials, parts, and capital or as non-tangible resources such as knowledge, information, and special capabilities. Resources may also take the form of products and services.

Note 8. Pfeffer and Salancik (1978/2003) also highlight conditions in which power derived from resource-dependent relationships is exerted to form dependence relationships that are advantageous to the entity with power.

\section{Copyrights}

Copyright for this article is retained by the author(s), with first publication rights granted to the journal.

This is an open-access article distributed under the terms and conditions of the Creative Commons Attribution license (http://creativecommons.org/licenses/by/4.0/). 